This is the author's post-print copy of the article published on

R\&D Management

https://doi.org/10.1111/radm.12347

\title{
Open Data for Open Innovation: Managing Absorptive Capacity in SMEs
}

\author{
Franz Huber \\ Seeburg Castle University, \\ Seeburgstrasse 8, 5201 Seekirchen am Wallersee, Austria. \\ franz.huber@uni-seeburg.at.
}

Thomas Wainwright

School of Management, Royal Holloway, University of London, Egham, Surrey, UK

tom.wainwright@rhul.ac.uk

Francesco Rentocchini

Department of Economics, Management and Quantitative Methods (DEMM), University of Milan, Italy

$\&$

Southampton Business School, University of Southampton, UK

francesco.rentocchini@unimi.it 
This is the author's post-print copy of the article published on

R\&D Management

https://doi.org/10.1111/radm.12347

\section{$\underline{\text { Abstract }}$}

Open Data (OD) utilisation has been encouraged by governments because of its potential to fuel digital innovation. Despite this, there is a paucity of study into the role of OD for SMEs, in contrast to the growing literature that has focused on the collection and sharing of OD by the public sector. As such, our study contributes to open innovation research by analysing the main capabilities needed to overcome existing barriers to successfully manage OD in SMEs. Building upon the recent SME-oriented OI literature and adopting an interpretative absorptive capacity framework, we analyse the data collected from 30 semi-structured interviews with experts working in UK organisations adopting OD-based OI strategies. We find a number of core factors that shape $O D$ acquisition, assimilation, transformation and exploitation by SMEs. Results show that without the specific OD capabilities identified in our study, it will be difficult for SMEs to successfully use OD, which may explain why the uptake of OD by SMEs more broadly has so far been limited. These unique OD capabilities need to be better developed by OD using SMEs, if this 'raw material' for the digital economy is to be fully exploited.

\section{Introduction}

Policymakers and researchers have highlighted the important role of innovative small and medium-sized enterprises (SMEs) in job creation and economic growth (Wolf \& Pett, 2006). More recently, digitization and Internet-based opportunities for information sharing have transformed the potential for open innovation (OI) in SMEs (Bogers et al. 2017; Dodgson et al., 2006; Huber, 2013; Whelan et al., 2010). This paper focuses on new developments in Open Data (OD) for SMEs, data that are published by organizations online and in machine- 
This is the author's post-print copy of the article published on

R\&D Management

https://doi.org/10.1111/radm.12347

readable format, for everybody to use and republish without financial costs (Open Data Institute 2015).

Researchers have argued that OD offers new opportunities for organizations, particularly SMEs, to develop new value-added applications or services as it is freely accessible (Chan, 2013; Janssen, 2011; Lee et al., 2014; Almirall 2015), which can increase their innovation potential (Dwivedi et al., 2017). Studies on OD have broadly focused on the publication of OD from a government-centric perspective, focusing on the benefits and risks of public sector OD publication (Hossain et al. 2016; Kucera and Chalpek 2014). Comparatively less research has covered how SMEs benefit from OD, focusing mainly on new OD business models (Magalhas and Rosera, 2017).

OI research has argued that the use of external assets can help SMEs overcome resource and capability constraints (Eftekhari and Bogers, 2016), manage the liability of smallness (Colombo et al. 2012) and increase revenue growth (Chesborough and Crowther 2006). Despite this, research by Almirall (2015) and Lee et al. (2014), has suggested that OD use, as part of OI mechanisms, has so far been unsuccessful in meeting its full potential, with organizations failing to commercialize OD into new digital products and/or services. This contrast contributes to our paper's problem formulation: on the one hand, academic literatures have pointed to the potential opportunities of OD for resource-constrained SMEs, where access to free, external data should be beneficial for OI. On the other hand, SMEs in the digital economy appear to struggle to capture the benefits of OD OI in practice. This suggests that SMEs may find it challenging to develop the absorptive capacity (Cohen and Levinthal, 1990) to recognize the value of OD assimilate it and apply it to commercial ends. This problem may undermine the ability of SMEs to contribute to the growth of the digital economy through OD based OI and is used to formulate the following question: what are the 
This is the author's post-print copy of the article published on

R\&D Management

https://doi.org/10.1111/radm.12347

challenges in adopting OD and what particular absorptive capacities do SMEs need to benefit from OD? There is limited research on the processes of OI in SMEs, and, specifically, a lack of research on the internal capabilities and human capital that they require to exploit the potential of OI (Wynarczyk et al, 2013). These research gaps raise important questions which makes OD based OI in SMEs a fruitful and important area of academic research. If datadriven SMEs and start-ups struggle to engage in OI with access to free data, then they may be likely to struggle further when using other free assets, hindering the potential contribution of OI more widely to the growth of the digital economy. Using the context of OD, we examine the understudied processes of SME OI to contribute to solving the problem as to why SMEs struggle to innovate with free resources.

Our paper aims to explore (i) the barriers to OD use; (ii) the specific OD absorptive capacity capabilities that shape OD activities in SMEs and (iii) how SMEs have benefited from the OD based OI. Based on 30 semi-structured interviews with organizations in the UK which consume and/or publish OD, our paper provides novel insights into the difficulties and benefits of pursuing OD-based OI. Our conceptual model, drawing upon the absorptive capacity framework of Zahra and George (2002), reveals the barriers to OD use and help to identify which capabilities are required in order to successfully utilise OD.

The remainder of this paper is structured as follows: section 2 will outline the OD, OI and absorptive capacity literatures and their relevance to SMEs. Section 3 describes the methodology. Section 4 examines types of barriers to OD, and the specific types of absorptive capacity capabilities that support SMEs in capturing value from OD, and the advantages of OD to SMEs. Section 6 will conclude the paper. 
This is the author's post-print copy of the article published on

R\&D Management

https://doi.org/10.1111/radm.12347

\section{Open data for SME open innovation}

Data is the 'raw material' of the digital age (Mayer-Schönbergerand and Cukier, 2013). Entrepreneurs and innovators are seeking new data sources to create value-added products and services through OI (cf. Bogers et al. 2017). Researchers have increasingly drawn attention to the importance of 'big data' (Bertot et al. 2014; Yoo et al 2012) and 'linked data' (Bizer et al. 2009) in innovation, but the recent phenomenon of OD remains comparatively understudied. The OD Movement gathered momentum from 2009, when the US government issued a Memorandum on Transparency and Open Government, which aimed to make more government data publicly available (Lee et al. 2014). Since 2009, European and emerging economy governments have also begun to publish OD, in addition to private sector organizations.

OD is digital and available in a machine readable format, which enables it to be used directly in innovative value-added applications or services (Chan, 2013; Janssen, 2011). OD often comprises of information on themes such as transportation, the environment, corporate filings, property, education and health, and is viewed by policy makers as an important resource for the growing digital economy (BIS 2014). This has resulted in the creation of transport apps using real-time transport OD, or real-estate search apps, which use OD to provide information on the quality of local amenities and their proximity to properties for sale or rent.

Although OD has attracted increasing interest from policymakers and practitioners, academic studies are rare and sporadic. On the one hand, given the technical roots of OD in web science, this discipline has examined technical processes and techniques including the 
This is the author's post-print copy of the article published on

R\&D Management

https://doi.org/10.1111/radm.12347

semantic web, ontologies and linked data, to advance the practical applications of OD (Jain et al. 2010; Missier et al. 2010; Oren et al. 2008). On the other hand, information management studies have examined OD's role in open government policies to enhance transparency, democracy and civic engagement (Janssen et al. 2012; Bates 2012). Despite this, there is surprisingly limited research on OD in management and innovation studies. Most of the studies in management and innovation which examine OD take a government-centric perspective. ${ }^{1}$ These works mainly focus on the benefits and risks to public administration OD publication (Wang and Lo, 2016; Zuiderwijk et al., 2012; Kucera and Chlapek, 2014; Van Veenstra and Van den Broek, 2013). For example, Hossain et al. (2016) survey the existing literature on OD and categorise barriers to OD publication, specifically individual, institutional, legal, technological and economic barriers. Similarly, Kucera and Chlapek (2014) discuss the benefits and risks of government OD in addition to solutions that mitigate the main barriers to OD publication. In all of the cases above, risks and benefits refer to the process of publishing data in an open format by public organisations.

In our view, this opens up two interrelated lines of enquiry. First, there is a lack of research in management and innovation studies on the benefits and risks of OD adoption. The decision to adopt inbound OD requires considerations that are qualitatively different to those of publishing outbound OD. For example, an adopter of external OD may need to be careful in nurturing and maintaining relationships with OD publishers to mitigate the risk that OD sources may ‘disappear’ or suffer from quality deterioration (Dawes et al, 2016).

Second, OD innovation brings different benefits and risks to private sector organisations and public administrations, which require different capabilities. In the context of government OD,

\footnotetext{
${ }^{1}$ There is a growing stream of the OD literature which focuses on the business models of private organisations and how they can adapt to extract value from OD (for an excellent survey of this stream of the literature please refer to Magalhas and Rosera, 2017). Although this is an interesting topic and further research is certainly needed, this is not the focus of our current work.
} 
This is the author's post-print copy of the article published on

R\&D Management

https://doi.org/10.1111/radm.12347

benefits refer to aspects such as increased transparency and citizen empowerment, which are likely to be enabled by effective data re-use practices and well-designed regulation (Dawes, 2010; Janssen et al., 2012). In contrast, private companies can improve efficiencies in their value chain (Estermann, 2014) and increase their innovation potential (Dwivedi et al., 2017), particularly when they position themselves as boundary organisations and take full advantage of mediated OD revealing (Perkmann and Schildt, 2015). Both points outlined above are particularly relevant for SMEs. It has often been argued that SMEs face innovation limitations due to a lack of slack resources and difficulties in forming external partnerships (Hewitt-Dundas, 2006), which impede the identification of new opportunities and externally available knowledge (Bianchi et al., 2010; Prajogo \& McDermott, 2014; Maes \& Sels, 2014).

The reuse of OD, as an external asset, can be considered as part of an OI mechanism. It has been suggested that OI mechanisms, as “purposefully managed knowledge flows across organizational boundaries” (Chesborough and Bogers, 2014, p.17), can help to address the innovation challenges faced by SMEs (Eftekhari and Bogers, 2016). For example, studies have argued that network formation with external partners can help overcome the liability of smallness (Colombo et al, 2012; Freeman et al., 1983; Gassmann et al, 2010), while enabling business and technological knowledge to be sourced (Huber, 2013). Furthermore, scholars have argued that OI increases new product development (Dahlander and Gann, 2010; Laursen and Salter, 2006; Piva et al., 2012), revenue growth (Chesbrough and Crowther, 2006) and financial performance (Rothaermel and Alexandre, 2009).

Benefiting from external resources does not happen automatically, but requires absorptive capacity: the ability to identify, value, assimilate and apply new external knowledge or assets (Cohen and Levinthal, 1990; Xia and Roper, 2016). SMEs, in contrast to larger organisations, tend to have fewer resources for utilizing external relationships (Colombo et al, 2012) and 
This is the author's post-print copy of the article published on

R\&D Management

https://doi.org/10.1111/radm.12347

show a lower tendency to collaborate with external partners (Ebersberger et al., 2012). However, their flexibility and lack of core rigidities, can benefit them in pivoting to capture new external opportunities (Colombo et al, 2012). SMEs require internal management and organizational capabilities to assimilate and apply external resources in inbound innovation activities (Brunswicker et al., 2015; Robertson et al, 2012), and a lack of multidisciplinary competencies (Bianchi et al, 2010) and less structured approach to innovation management (De Toni and Nassimbeni, 2003) may be problematic.

This problem is also relevant to the case of OD. Key protagonists of the OD Movement have argued that OD can be used to create new digital innovations, although widespread success has so far has been illusive (Lee et al. 2014), despite the notion that access to free data creates new opportunities for OI. We posit that SMEs willing to use and publish OD face a number of challenges and that they need to develop specific capabilities to adopt and exploit OD. In doing so, we explore the capabilities needed to overcome barriers and exploit benefits of the adoption of OD by SMEs. We do this by drawing upon the absorptive capacity and OI literatures, which contribute to our understanding of OD OI in SMEs.

The theoretical perspective of absorptive capacity as "the ability of a firm to recognize the value of new, external information, assimilate it, and apply it to commercial ends” (Cohen and Levinthal, 1990, 128) provides a useful lens for examining this problem. Specifically, we apply the framework of absorptive capacity by Zahra and George (2002) to examine various stages of the inbound utilisation of OD. The stage of acquisition refers to the capability needed to identify and acquire externally generated OD, whereas assimilation concerns the capability to process, interpret, and understand OD (c.f. Zahra and George, 2002). Furthermore, full utilization of OD requires the additional capability to combine externally acquired and assimilated OD with existing internal knowledge in the transformation stage. 
This is the author's post-print copy of the article published on

R\&D Management

https://doi.org/10.1111/radm.12347

The final stage is the capability of exploiting OD for developing new products, services or processes. The differentiation between, and substantiation of, these stages enables a deeper analysis of the challenges and required capabilities to successfully benefit from OD.

\section{Methodology}

This paper draws upon an interpretive qualitative approach (Gephart 2004) to obtain accounts of how OD based OI takes place, particularly the benefits and barriers of using OD and the capabilities required for absorptive capacity. The data consists of 30 semi-structured interviews with experts working in UK organisations adopting and OD-based OI strategies, complemented by online information and documents of the respective organisations.

The UK is central to the OD Movement, as it was one of the first countries to introduce legislation requiring government departments to publish OD in 2012 (BIS 2014). Furthermore, the activities of key OD protagonists including Sir Tim Berners-Lee (inventor of the World Wide Web) and Sir Nigel Shadbolt (chairman of the Open Data Institute), are based in the UK. This approach enables us to address the problem identified in Section 2, by providing insight into the acquisition, assimilation, transformation and exploitation of OD to enable a deeper analysis of the required capabilities needed to successfully benefit from OD. Understanding how OD is published by public and corporate organisations is important to determine how OD is positioned for its inbound use by SMEs. We deliberately chose to target a variety of organisations, including SMEs, public sector OD publishers and larger corporations to gain a more holistic picture of the OD ecology and to provide insight into the research question from different perspectives. In particular, the comparison of SMEs vs. large organisations enables a contextualisation of OD barriers, capabilities and benefits for SMEs, and the perspective of public organisations as key publishers of OD and key relational actors can be integrated. Keeping a broad view at this stage seems also relevant in relation to the 
This is the author's post-print copy of the article published on

R\&D Management

https://doi.org/10.1111/radm.12347

recent interest developed within the OI literature on the important role of platforms and ecosystems for OI (West et al., 2014). To select relevant cases, the researchers used the ODI's membership list and examples from data.gov, along with snowballing, to access respondents in the OD developer community. In total, 37 OD organisations were contacted, 30 of which responded, and we could not identify clear patterns for non-response. The characteristics of the organisations interviewed are shown in Appendix 1. Following the established 'key informant interviews' approach (Squire et al, 2009), interviewees were key decision makers on OD in the respective organisation, and the job positions included chief information officers, heads of data and statistics, owner-managers, and product/innovation managers (see Appendix 1).

A semi-structured interview guide was used to ensure consistency and that similar issues were examined in all cases, with sufficient flexibility and room to capture issues that interviewees thought important to their organisation (cf. Biniari 2012). Interviews lasted between 45 minutes and two hours, were recorded and later transcribed. Face to face interviews were conducted by all three authors in the UK, between 2014-2015 to assist in the contextualisation of the information provided, although some organisations insisted on Skype interviews because of flexible working routines (see Appendix 1). The interviews examined the experiences of using inbound and outbound OI, with a focus on the absorptive capacities needed to exploit OD within the organisation. Credibility probes were used in the interviews to undermine strategic impression management (Rubin and Rubin, 2011). Respondent data was anonymised to protect the identities of the interviewees and their organisations.

The analysis used a multi-step iterative process, drawing upon theoretical issues identified earlier in the literature (Section 2, in particular on OD challenges and SME capabilities for OI) and inductive reasoning to shape the conceptual development (Miles et al., 2013). 
This is the author's post-print copy of the article published on

R\&D Management

https://doi.org/10.1111/radm.12347

Inspired by the Gioia methodology (Gioia et al, 2013), we aimed to develop a data structure by first identifying 1st order categories (interviewee-centric terms). Then we explored linkages and patterns within 1st order categories and developed 2nd order themes (researchercentric themes). Afterwards, we synthesised the 2nd order themes into aggregate dimensions. Whilst the interview data constituted the core for these steps, we also utilised information on organisational websites, API blogs, company reports and other documents, if available, to verify or enrich the arguments.

Our analysis used critical verification techniques to optimise validity in the interviews (Morse et al., 2008), which involved double-checking coded themes and their interpretation, whilst undertaking a critical interpretation of the transcripts, to avoid biased memorising. To optimise validity, we applied data triangulation (utilising online information and documents in addition to the interview data) and investigator triangulation (three researchers collected data and two researchers independently coded 1st order concepts and 2nd order themes) (Denzin, 1978). Whilst there are challenges in developing robust generalisations from qualitative studies, this study proposes a conceptual framework of the capabilities needed to successfully develop new digital applications and services from OD.

\section{Findings}

To address the problem as to why SMEs may struggle to exploit OD, we seek to highlight the specific barriers that SMEs face in consuming external OD, before examining the unique capabilities that are required to overcome these barriers, and the OI benefits that emerge from developing and using these capabilities. In the following findings section, we explore the barriers, capabilities and benefits that affect the absorptive capacity dimensions of acquisition and assimilation, transformation and exploitation (cf. Zahra and George 2002). 
This is the author's post-print copy of the article published on

R\&D Management

https://doi.org/10.1111/radm.12347

\subsection{Open data acquisition and assimilation}

Acquisition as the capability needed to identify and acquire external knowledge, and assimilation, as the capability needed to process, interpret, and understand external knowledge, are conceptually different stages in Zahra and George's (2002) absorptive capacity framework. Yet, our results suggest that in the context of OD these two stages are intertwined and can be regarded as one stage in the absorptive capacity process. We argue that modern data interfaces and portals, for example application programming interfaces (APIs), make the technical act of OD acquisition easier, to take advantage of mediated OD revealing (Perkmann and Schildt 2015). However, identifying relevant OD requires assimilation capabilities of interpreting and understanding the nature and relevance of OD. Difficulties in identifying relevant OD that can be combined with proprietary data and expertise to create new products and services, is an important OD acquisition and assimilation barrier. Locating relevant OD sources can be challenging, due to the increasing volume of OD sources, but also the absence of centralised repositories. This requires the time consuming task of searching multiple repositories, individual websites, professional networks and social media, as highlighted in the following extract:

“...all these government or quasi-government bodies are publishing their data. But unfortunately that varies from township all the way up to central government, and each one is doing it in their own format, and it's just an absolute nightmare to get an overview just in terms of the data...discovery is a challenge...maybe there's a service to be built around just helping people discover... I mean it's kind of a nebulous community, although we are active in that community.” (Case 16) 
This is the author's post-print copy of the article published on

R\&D Management

https://doi.org/10.1111/radm.12347

Access to OD does not automatically lead to correct interpretations and understandings of its context and meaning. In the example of Case 17, sources labelled as OD, may not be fully open and transparent creating additional problems of assimilation, even if the source has been identified and discovered:

'[Organization P] were obliged to make that data available to the public. But they put it in a format which is very, very complicated for use, and I think for them it was a bit of a conflict of interests, because they wanted to do some stuff themselves...And I think as a result, they ticked the box in saying “This data is publicly available and you can use it” but actually made it hard to do so...there were a few gaps missing from the data, there were no instructions on how to use it. They didn't have an API or anything. It was done in a strange fashion I'd say in terms of making it available, but technically it is available now to people’ (Case 17)

In order to overcome this barrier, the $\mathrm{OD}$ acquisition and assimilation capability that is particularly important to OD SMEs, is the ability to engage with OD publishers (see Figure 1). This enables SMEs that are adept with requisite knowledge of OD to network and locate publishers of relevant OD sources, and to understand the contexts in which the OD was created, and to shape its publication, as a precursor to assimilating the OD into new products and services.

Furthermore, the fuzzy nature of OD makes its assimilation difficult if it is not fully 'open', by accident or design, making it more important to have the ability to develop an organisational culture that is willing to promote and adopt OD. Case 17 was seeking to create a novel service, and the data source required could not be purchased, making the ability to 
This is the author's post-print copy of the article published on

R\&D Management

https://doi.org/10.1111/radm.12347

develop an organisational culture for OD more important, especially the willingness to keep working through problems with OD use. Larger organisations, in contrast, such as Case 26 when they found an OD source was not granular enough and did not cover sufficient geographical regions, simply paid for a new source of data to be generated as they have more resources (c.f. Colombo et al. 2012), and were looking to use OD to support their core business activities, rather than to form a central component of it, in creating an innovative new product.

The first OD acquisition and assimilation benefit for SMEs is the access to new and previously unavailable data. The availability of data that was previously 'closed', but also commercially unavailable, enabled the development of novel products (see Figure 1), facilitated by the ability to pivot, whereas larger organisations focussed on the free attributes of $\mathrm{OD}$ as a practice to reduce costs, as highlighted by the following case:

“It's just data. If we have to pay for it, we have to pay for it; if it’s there, it's there and we go hunt stuff down off the internet all the time. So I think it's something that we have always done, and we don't see it as this big new way of data, it's just adding to what we have to do. We might have to read a few more blogs to find out what has been released, and what's going on where, and how to get hold of the stuff.” (Case 1).

In contrast, for SMEs it is not merely about cost-reduction, but about the fundamental commercial possibility to develop new products in the first place (Huber 2013; Dahlander and Gann 2010) (see Figure 1 for additional quotes).

A second type of OD acquisition and assimilation benefit for SMEs comes mainly from proprietary data substitution as its free status provides accessibility to OD, which previously 
This is the author's post-print copy of the article published on

R\&D Management

https://doi.org/10.1111/radm.12347

in some cases had a charge, which disincentivised its use (see Figure 1). As highlighted above, OD is desirable to larger organisations as it can improve operational efficiency (i.e. cost cutting), but for SMEs and start-ups that need a particular data source, accessing OD can entirely remove an important financial barrier (see Figure 1). This means that for SMEs, the availability of OD enables experimentation and the development of new products and services, where higher costs of critical proprietary data would have previously left entrepreneurs unable to capture an opportunity (see Figure 1). Subsequently, the flexibility and lack of core rigidities, enables SMEs to scope for new potential opportunities through OD (Colombo et al. 2012)

\section{[FIGURE 1 AROUND HERE]}

\subsection{Open data transformation}

The transformation stage focuses on the capability of combining newly assimilated knowledge with existing knowledge, so that the latter can be used in new ways (Lane et al., 2006; Zahra and George, 2002). Once SMEs have begun to assimilate OD it undergoes transformation as it is integrated into potential new products and services. SMEs struggle to exploit OD, despite it being a free resource, due to OD transformation barriers, particularly around having the skills to integrate $\mathrm{OD}$, partly related to the shortage of data scientists that can utilise OD (see Figure 2). The digital economy has grown rapidly, and the demand for skilled data scientists to process data has also increased, but as the profession of data scientist is new, there is limited expertise in the field, leading to high demand. The availability of data scientists with OD expertise is even scarcer, which is particularly problematic for SMEs who are often short of organizational capabilities and a lack of multi-disciplinary competencies 
This is the author's post-print copy of the article published on

R\&D Management

https://doi.org/10.1111/radm.12347

(Robertson et al. 2012; Bianchi et al. 2010). Case 16 has sought to recruit less experienced, cheaper data scientists, choosing to develop and train them with OD expertise. While this partially overcame the transformation barrier, they found it difficult to retain the expertise, losing them to larger organizations, with more resources:

“...it's very easy for us to hire 25 year olds; it's almost impossible for us to keep [them], because at the point they get married, want to have a family, have a family, but where is the kid going to school? If they are not from the UK they want to go back to their home country, so it's our biggest problem in the business. You can get young inexperienced people; it's very difficult to keep enough let's say, older, experienced people, so it's a huge problem” (Case 16)

To overcome this barrier, successful OD SMEs developed OD transformation capabilities, developing the ability to hire and integrate talent as highlighted above (Figure 2). As Case 8 explained, unique start-ups can attract diverse expertise if they are differentiated. In contrast to the broader digital economy, the values of OD are attractive to different communities of practice, acting as a central bonding point that would interest like-minded individuals, especially if OD is central to the SMEs business:

"I guess the second major area that I would highlight is being unique gets a mix of talent. [...] The bigger challenge is because those people culturally tend to be quite different, just getting them to work together... I think that putting open data into this type of community is probably the best bet, because it's a group of people who have grown up with this concept of embracing open...even for non-technical people within the entrepreneurial community” (Case 8) 
This is the author's post-print copy of the article published on

R\&D Management

https://doi.org/10.1111/radm.12347

Spanning the boundaries of different professions in OI is important and can be challenging (Fleming and Waguespack 2007; West and Lakhani 2008). The transformation capability of bridging data science and marketing was also important in OD OI (see Figure 2), which required the ability to train and develop talented younger staff.

The transformation benefits emerge from the integration of OD and proprietary data that begins to add value to the OD, although this is contingent on the development of capabilities to transform the OD into a useful product or service for end users. As Case 23 explained:

“...we became aware that there were a lot of datasets available out there; they were free, but hard for people to use; organisations were finding them too much that they either they were struggling to access this data, or they were avoiding accessing the data because it was going to be too much hassle to get hold of it, or they didn't have the skills or resources in house to do it. So we just sort of saw the opportunity there” (Case 23)

The value of OD often emerges when it is integrated with proprietary data in the creation of a new application or service, where skills and expertise unleash OD’s value. Users without expertise and skills are unable to exploit OD's value effectively, so SMEs that are able to develop and retain staff with OD and multidisciplinary competencies (Bianchi et al. 2010) were able to use this as a competitive advantage.

[FIGURE 2 AROUND HERE]

\subsection{Open data exploitation}


This is the author's post-print copy of the article published on

R\&D Management

https://doi.org/10.1111/radm.12347

OD exploitation as the capability of applying the transformed knowledge for innovations, is our third absorptive capacity dimension, and the final step to utilising OD, with a different set of exploitation barriers and exploitation capabilities that lead to benefits of using OD (see Figure 3). The successful exploitation of OD is complex, but relies on unique capabilities to create value from OD, which arguably had no inherent value in itself:

\footnotetext{
"When you first talk to them, they say "Oh but it's free" which is everyone's argument in relation to it [OD], but as my argument always goes, is well clay has always been in the fields, but you don’t go and make your own plates” (Case 21)
}

One important exploitation barrier is uncertainty around the future availability of OD. While accessing external resources can grow revenue and enable product development (Dahlander and Gann 2010, Laursen and Salter 2006; Piva et al. 2012), the closure of an OD source could have a substantial and negative effect on an SME's products and services. Case 5 developed a product and tested it with potential customers, before a core source of external OD was closed, leading to product failure. Case 5 was creating multiple products using OD, which mitigated the effect of this event, but this barrier is one of particular concern for SMEs. A second exploitation barrier involved the quality of OD from external publishers and the risk that if there were errors in the OD, then it could lead to a service failure of the SME's product. This could then incur legal and/or reputational risks, whereas if the source was paid for proprietary data, there would be clearer lines of responsibility and liability. The most interesting exploitation barrier was concern for the risk of imitation - which was not misplaced. If a competitor can identify the OD sources used by a SME, then their product or service can be easier to copy, in contrast to if the data was proprietary or self-generated. Cases 2 and 16 had published their own OD to attempt to grow their business through 
This is the author's post-print copy of the article published on

R\&D Management

https://doi.org/10.1111/radm.12347

coupled-OI and found that some competitors had copied their products and created fake replica websites using their OD, undermining their business.

Exploitation capabilities are particularly important, including the ability to develop a robust business case (Figure 3). As highlighted above with the barrier of imitation, SMEs need to carefully consider how to make the case and to develop OD in the business, particularly when designing the products and organisation, to ensure that the SME is designed with openness in mind, while appropriating the returns on OD based innovation (Hurmelinna-Laukkanen and Puumalainen, 2007). In addition to managing risks, the SME has to be developed around external opportunities such as access to OD sources. This makes the capability of relationship management skills important, to minimise the risk of imitation, but to also manage relationships and to lobby for the release of new OD sources and to influence their publication format. While SMEs often struggle to form external partnerships to access knowledge (Prajogo and McDermott 2014; Maes and Sels 2014), it is critical that they build relations with OD publishers. For example, Cases 16 and 8 noted how they are able to work with government departments and feedback on what OD should be published, and what the data standards should be, to make OD exploitation easier. SMEs highlighted how the capability for continuous innovation was important in escaping the risk that their products and services could be copied, as OD reduces barriers to entry and imitation. The ability to improve their products and services continually was viewed as a strategy that would improve the products while protecting the business.

The exploitation benefits for OD-using SMEs are scaling-up through coupled OI and the creation of novel OD-dependant product and services (c.f. Chesbrough and Bogers 2014; Dahlander and Gann 2010). As Cases 2 and 8 explain (Figure 3), by publishing their own OD, other external developers were able to use it to create their own businesses as affiliates. 
This is the author's post-print copy of the article published on

R\&D Management

https://doi.org/10.1111/radm.12347

This functioned as coupled OI. For example, Case 2 as a retailer opened its inventory catalogue as real-time OD, so overseas entrepreneurs could create apps for their local markets, acting as affiliates. This enabled the affiliates to attract overseas customers on behalf of Case 2. The affiliate apps using real-time OD, would then pass customer orders on to Case 2, for which they would receive a referral fee. This enabled Case 2 to grow and internationalise with limited resource expenditure. By publishing their OD, they did not have to actively seek and attract affiliate partners, while the open nature widened the potential number of affiliates. This enabled SMEs that are effective at building relationships (Colombo et al. 2012) to enhance their revenue growth and performance (Chesbrough and Crowther 2006; Rothaermel and Alexandre 2009).

Novel OD-dependant product and service creation are the second exploitation benefit. As highlighted in Case 5 (Figure 3), for example, new OD became available that could not be previously purchased, which enabled them to develop products and services that permit clients to compare private care providers, using government audit and review OD. Before this OD was published, it would have not have been possible to develop the app. The availability of data, together with the ability of the firm to understand in advance what customers wanted, allowed them to develop a novel OD-dependent product/service.

[FIGURE 3 AROUND HERE]

\section{Concluding discussion: an open data absorptive capacity framework}


This is the author's post-print copy of the article published on

R\&D Management

https://doi.org/10.1111/radm.12347

OI has substantial potential in the Digital Age, where data is a key external asset that can be used to develop novel products and services (Mayer-Schonbergerand and Cukier 2013). OD in particular, has the potential to form part of the digital economy's backbone and provide a possible engine of growth. Despite its prominence in public sector research, there is a paucity of study on the role of OD for business, as most of the recent work in the field of OD has mainly focused on the generation of OD by the public sector (for example, Wang and Lo 2016; Zuiderwijk et al., 2012). This is particularly unfortunate because the value of OD emerges from its re-use, and the requisite mechanisms are still far from being fully understood and realised. While research has examined how OD can develop efficiencies and innovation potential (Estermann 2014; Dwiviedi et al. 2017), there is an absence of research on the mechanisms that create new value.

On the one hand, academic literatures have indicated how OD can help SMEs overcome resource constraints through OI (Wynarczek et al. 2013), but on the other hand, they seem to struggle to capture OD’s value in practice (Almirall 2015). Our study can be seen as instrumental in filling the above gap, but in specifically addressing the problem as to why SMEs struggle to use OD. The OD barriers, capabilities and benefits that shape SME OD innovation, have been assembled adopting the interpretative framework provided by Zahra and George's (2002) absorptive capacity dimensions of acquisition, assimilation, transformation and exploitation in Figure 4. Flows indicate the processes and mechanisms, where capabilities surmount barriers and lead to OD benefits. We have argued that in the context of OD, the stages of acquisition and assimilation are highly intertwined and should be regarded as one stage on the absorptive capacity process. This helps address the problem as to why SMEs struggle to use OD, by highlighting the overall barriers that can undermine the ability of SMEs to use OD successfully, but also the specific OD capabilities that are required 
This is the author's post-print copy of the article published on

R\&D Management

https://doi.org/10.1111/radm.12347

to overcome these barriers, helping to generate the absorptive capacity that capture the benefits from the successful exploitation of OD.

Building upon Zahra and George's (2002) framework, we contend that the identified OD capabilities can be divided into two types: potential ACAP and realised ACAP. The capability of engaging with OD publishers and benefit of accessing previously unavailable data, in addition to the ability to develop an organisational culture for OD, leading to the benefit of proprietary data substitution, are classified as potential absorptive capacities. They are necessary early stages to enable SMEs to scale-up through affiliates, or to develop novel OD-dependent products and services, but they are not in themselves sufficient to fully harness OD. The realised absorptive capacities become important as a mix of talent is needed to integrate OD with closed data, while developing the ability to bridge traditional and nontraditional expertise is central in transforming the OD prior to its exploitation steps. Exploitation required capabilities for continuous innovation using OD, the ability to develop a business case, while undertaking relationship management to avoid imitation by competitors and to develop the legal abilities to mitigate legal and reputational risks, before the unique OD benefits of scaling-up through affiliation or novel OD-dependent products and services can be achieved. Based on our empirical analysis, we argue that without the specific OD potential and realised capabilities identified in Figure 4, it will become difficult for SMEs to successfully use OD, which may explain why the uptake of OD by SMEs has so far been limited (Lee et al. 2014).

From this perspective, our study contributes to OI research by analysing the main capabilities needed to overcome existing barriers to OD utilisation and to successfully manage OD in SMEs. SMEs face considerable challenges in forming networks with external partners (Eftekhari and Bogers 2016; Colombo et al,. 2012), and limited internal capabilities and a 
This is the author's post-print copy of the article published on

R\&D Management

https://doi.org/10.1111/radm.12347

lack of multidisciplinary competencies can undermine their ability to assimilate and exploit external data (Brunswicker et al., 2015; Bianchi et al., 2010). The unique capabilities identified in our paper are central to the absorptive capacity of SMEs and their ability to undertake OI in the digital economy. Building upon recent insights from the OI literature, particularly on OI in SMEs, and adopting an interpretive absorptive capacity framework, we have highlighted a number of core factors contributing to OD acquisition, assimilation, transformation and exploitation by SMEs.

\section{[FIGURE 4 AROUND HERE]}

To conclude, this paper developed a novel OD absorptive capacity framework to systematically highlight and specify why utilizing OD is not 'free' but requires considerable capabilities. The study addresses the research gap on the internal capabilities that SMEs require to exploit the potential of OI (Wynarczyk et al, 2013). The results show that the wellknown problem of resource constraints in SMEs bites again (Hewitt-Dundas, 2006), as SMEs tend to struggle to develop internal organizational capabilities to utilize external knowledge (Brunswicker et al, 2015; Robertson et al., 2012) and are often restricted by a lack of multidisciplinary competencies (Bianchi et al., 2010). Developing those capabilities is nontrivial, especially for micro and small firms.

Policymakers and practitioners need to be aware of the absorptive capacity requirements of OD, and address how SMEs can be best supported, and how actors in the OD innovation ecology can interact and cooperate to unleash the potential of OD for SME innovation. This may require investment and training to assist SMEs in identifying gaps and to develop the 
This is the author's post-print copy of the article published on

R\&D Management

https://doi.org/10.1111/radm.12347

capacity requirements needed to make them more successful in digital innovation. OD publishers, particularly in the public sector, could provide more support to SMEs, to assist their learning on managing relationships with publishers, while supporting SME skill and expertise development for OD based OI. Currently, public sector agencies in the UK are required to publish OD, but amendments to regulation could call for them to provide additional support to users. This is particularly important as many novel and radical innovations that form part of the digital economy are developed by SMEs, emerging from niche sectors that corporations may overlook. Policy-makers need to support SMEs that participate in the OD ecology, to develop the absorptive capacity necessary to facilitate innovation and to support the digital economy’s growth.

Future research needs to examine the ability of SMEs to deal with and utilize data, whether open or proprietary, as a key challenge for innovation in the evolving Digital Age. Study is also needed to examine resource constrained strategies for integrating external data in more detail, and to examine how coping strategies and additional support mechanisms could be developed to assist OI in SMEs. Furthermore, future research should examine the roles various types of organisations (public and private organisations of different sizes) can play in the emerging OD innovation ecology (van der Borgh et al., 2012). Developing more detailed insight into these areas will enable practitioners and policy developers to address the barriers to SMEs in the digital economy.

\section{References}

Bates, J. (2012) 'This is what modern deregulation looks like': co-optation and contestation in the shaping of the UK's Open Government Data Initiative. The Journal of Community 
This is the author's post-print copy of the article published on

$\mathrm{R} \& \mathrm{D}$ Management

https://doi.org/10.1111/radm.12347

Informatics, 8(2). Available at: <http://ci-journal.net/index.php/ciej/article/view/845/916>.

Date accessed: 14 Mar. 2017.

Bertot, J. C., Gorham, U., Jaeger, P. T., Sarin, L. C., and Choi, H (2014) Big data, open government and e-government: Issues, policies and recommendations, Information Polity 19(2), 5-16.

Bianchi, M., Campodall 'Orto, S., Frattini, F., and Vercesi, P. (2010) Enabling open innovation in small-and medium-sized enterprises: how to find alternative applications for your technologies. R\&D Management, 40(4), 414-431.

Biniari, M. G. (2012) The emotional embeddedness of corporate entrepreneurship: the case of Envy. Entrepreneurship Theory and Practice, 36(1), 141-170.

BIS (2014) Open Data Strategy 2014-2016. BIS: London

Bizer, C., Heath, T., and Berners-Lee, T. (2009) Linked data-the story so far, International Journal on Semantic Web and Information Systems, 5(3), 1-22.

Bogers, M., Zobel, A.K., Afuah, A., Almirall, E., Brunswicker, S., Dahlander, L., Frederiksen, L., Gawer, A., Gruber, M., Haefliger, S. and Hagedoorn, J. (2017) The open innovation research landscape: Established perspectives and emerging themes across different levels of analysis. Industry and Innovation, 24, 8-40.

Brunswicker, S., and Vanhaverbeke, W. (2015) Open innovation in small and medium-sized enterprises (SMEs): External knowledge sourcing strategies and internal organizational facilitators. Journal of Small Business Management, 53(4), 1241-1263. 
This is the author's post-print copy of the article published on

R\&D Management

https://doi.org/10.1111/radm.12347

Chan, C.M. (2013) From open data to open innovation strategies: Creating e-services using open government data. System Sciences (HICSS), 2013 46th Hawaii International Conference on System Sciences, 1890-1899.

Chesbrough, H., and Bogers, M. (2014) Explicating open innovation: Clarifying an emerging paradigm for understanding innovation. In H. Chesbrough, W. Vanhaverbeke \& J. West (Eds.), New Frontiers in Open Innovation, pp. 3-28, Oxford: Oxford University Press.

Chesbrough, H., and Crowther, A. K. (2006) Beyond high tech: early adopters of open innovation in other industries. R\&D Management, 36(3), 229-36.

Cohen, W. M., and Levinthal, D. A. (1990) Absorptive capacity: A new perspective on learning and innovation. Administrative Science Quarterly, 35(1), 128-152.

Colombo, M. G., Laursen, K., Magnusson, M., and Rossi-Lamastra, C. (2012) Introduction: Small business and networked innovation: Organizational and managerial challenges. Journal of Small Business Management, 50(2), 181-190.

Dahlander, L., \& Gann, D. M. (2010) How open is innovation?. Research Policy, 39(6), 699709.

Dawes, S. (2010) Stewardship and usefulness: Policy principles for information-based transparency. Government Information Quarterly, 27(4), 377-383.

Denzin, N. K. (1978). The research act: A theoretical introduction to research methods. New Brunswick, NJ: Aldine Transaction. 
This is the author's post-print copy of the article published on

R\&D Management

https://doi.org/10.1111/radm.12347

De Toni, A., and Nassimbeni, G. (2003) Small and medium district enterprises and the new product development challenge: evidence from Italian eyewear district. International Journal of Operations \& Production Management, 23(6), 678-697.

Dodgson, M., Gann, D. and Salter, A., (2006) The role of technology in the shift towards open innovation: the case of Procter \& Gamble. R\&D Management, 36(3), 333-346.

Dwivedi, Y., Janssen, M., Slade, E., Rana, N., Weerakkody, V., Millard, J., Hidders, J. and Snijders, N. (2017) Driving innovation through big open linked data (BOLD): Exploring antecedents using interpretive structural modelling, Information Systems Frontiers, 19(2), 197-212.

Ebersberger, B., Bloch, C., Herstad, S. J., and Van De Velde, E. L. S. (2012) Open innovation practices and their effect on innovation performance. International Journal of Innovation and Technology Management, 9(06), 1-23.

Eftekhari, N., and Bogers, M. (2015) Open for entrepreneurship: how open innovation can foster new venture creation. Creativity and Innovation Management, 24(4), 574-584.

Estermann, B. (2014) Diffusion of open data and crowdsourcing among heritage institutions: Results of a pilot survey in Switzerland, Journal of Theoretical and Applied Electronic Commerce Research, 9(3), 15-31

Fleming, L. and Waguespack, M. (2007) Brokerage, Boundary Spanning, and Leadership in Open Innovation Communities. Organization Science 18(2), 165-180

Freeman, J., Carroll, G. R., and Hannan, M. T. (1983) The liability of newness: Age dependence in organizational death rates. American Sociological Review, 48(5), 692-710. 
This is the author's post-print copy of the article published on

R\&D Management

https://doi.org/10.1111/radm.12347

Gassmann, O., Enkel, E., and Chesbrough, H. (2010) The future of open innovation. R\&D Management, 40(3), 213-221.

Gephart, R. P. (2004) Qualitative research and the Academy of Management Journal. Academy of Management Journal, 47, 454-462.

Gioia, D.A., Corley, K.G. and Hamilton, A.L., 2013. Seeking qualitative rigor in inductive research: Notes on the Gioia methodology. Organizational research methods, 16(1), pp.15-31.

Hossain, M.A., Dwivedi, Y.K. and Rana, N.P., 2016. State-of-the-art in open data research: Insights from existing literature and a research agenda. Journal of organizational computing and electronic commerce, 26(1-2), pp.14-40.

Huber, F. (2013) Knowledge-sourcing of R\&D workers in different job positions: Contextualising external personal knowledge networks. Research Policy, 42(1), 167-179.

Hurmelinna-Laukkanen, P., and Puumalainen, K. (2007) Nature and dynamics of appropriability: strategies for appropriating returns on innovation. R\&D Management, 37(2), 95-112.

Jain, P., Hitzler, P., Sheth, A.P., Verma, K. and Yeh, P.Z. (2010) Ontology alignment for linked open data. International Semantic Web Conference, 402-417.

Janssen, K., (2011) The influence of the PSI directive on open government data: An overview of recent developments. Government Information Quarterly, 28(4), 446-456.

Janssen, M., Charalabidis, Y., and Zuiderwijk, A. (2012) Benefits, Adoption Barriers and Myths of Open Data and Open Government, Information Systems Management, 29(4), 258268 
This is the author's post-print copy of the article published on

R\&D Management

https://doi.org/10.1111/radm.12347

Kucera, J., and Chlapek, D. (2014) Benefits and risks of open government data, Journal of Systems Integration, 5(1), 30.

Lane, P. J., Koka, B. R., and Pathak, S. (2006) The reification of absorptive capacity: A critical review and rejuvenation of the construct. Academy of management review, 31(4), 833-863.

Laursen, K., and Salter, A. (2006) Open for innovation: the role of openness in explaining innovation performance among UK manufacturing firms. Strategic Management Journal, 27(2), 131-150.

Lee, M. J., Almirall, E. and Wareham, J. D. (2014) Open Data \& civic apps: 1st generation failures - 2nd generation improvements. ESADE Business School Research Paper, No. 256. Available at SSRN: https://ssrn.com/abstract=2508358

Lowik, S., Van Rossum, D., Kraaijenbrink, J., and Groen, A. (2012) Strong ties as sources of new knowledge: how small firms innovate through bridging capabilities. Journal of Small Business Management, 50(2), 239-256.

Maes, J., and Sels, L. (2014) SMEs' radical product innovation: the role of internally and externally oriented knowledge capabilities. Journal of Small Business Management, 52(1), 141-163.

Mayer-Schönberger, V. and Cukier, K. (2013) Big Data: a revolution that will transform how we live, work, and think. New York: Houghton Mifflin Harcourt.

Miles, M. B., Huberman, A. M., \& Saldana, J. (2014). Qualitative data analysis: a methodssourcebook. 3rd edition. Thousand Oaks: Sage 
This is the author's post-print copy of the article published on

R\&D Management

https://doi.org/10.1111/radm.12347

Missier, P., Sahoo, S.S., Zhao, J., Goble, C. and Sheth, A. (2010) Janus: from workflows to semantic provenance and linked open data. In International Provenance and Annotation Workshop (pp. 129-141). Berlin and Heidelberg: Springer.

Morse, J. M., Barrett, M., Mayan, M., Olson, K., and Spiers, J. (2008) Verification strategies for establishing reliability and validity in qualitative research. International Journal of Qualitative Methods, 1(2): 13-22.

Open Data Institute (2015) Open data means business: UK innovation across sectors and regions. London, UK

Oren, E., Delbru, R., Catasta, M., Cyganiak, R., Stenzhorn, H. and Tummarello, G., 2008. Sindice. com: a document-oriented lookup index for open linked data. International Journal of Metadata, Semantics and Ontologies, 3(1), pp.37-52.

Piller, F., and West, J. (2014). Firms, users, and innovation. H. Chesbrough, W. Vanhaverbeke and J. West (Eds.), New frontiers in open innovation, Ch. 2, Oxford University Press.

Perkmann, M., and Schildt, H. (2015). Open data partnerships between firms and universities: the role of boundary organizations. Research Policy, 44(5), 1133-1143.

Piva, E., Rentocchini, F., and Rossi-Lamastra, C. (2012) Is open source software about innovation? Collaborations with the open source community and innovation performance of software entrepreneurial ventures. Journal of Small Business Management, 50(2), 340-364.

Prajogo, D., and McDermott, C. M. (2014) Antecedents of service innovation in SMEs: comparing the effects of external and internal factors. Journal of Small Business Management, 52(3), 521-540. 
This is the author's post-print copy of the article published on

Robertson, P. L., Casali, G. L., and Jacobson, D. (2012) Managing open incremental process innovation: absorptive capacity and distributed learning. Research Policy, 41(5), 822-832.

Rothaermel, F. T., and Alexandre, M. T. (2009) Ambidexterity in technology sourcing: The moderating role of absorptive capacity. Organization Science, 20(4), 759-780.

Rubin, H. J., and Rubin, I. S. (2011) Qualitative interviewing: The art of hearing data. Thousand Oaks, CA: Sage.

Squire, B., Cousins, P., \& Brown, S. (2009). Cooperation and knowledge transfer within buyer-supplier relationships: the moderating properties of trust, relationship duration and supplier performance.British Journal of Management, 20(4), 461-477.

van Veenstra, A.F. and van den Broek, T.A., 2013, September. Opening moves-drivers, enablers and barriers of open data in a semi-public organization. In International Conference on Electronic Government (pp. 50-61). Springer, Berlin, Heidelberg.

Wang, H.J. and Lo, J., 2016. Adoption of open government data among government agencies. Government Information Quarterly, 33(1), pp.80-88.

West, J., and Lakhani, K. (2008) Getting Clear About Communities in Open Innovation. Industry \& Innovation, 15(2), 223-231

West, J., and Bogers, M. (2014). Leveraging external sources of innovation: a review of research on open innovation. Journal of Product Innovation Management, 31(4), 814-831.

West, J., Salter, A., Vanhaverbeke, W., and Chesbrough, H. (2014). Open innovation: The next decade. Research Policy, 43(5), 805-811. 
This is the author's post-print copy of the article published on

$\mathrm{R} \& \mathrm{D}$ Management

https://doi.org/10.1111/radm.12347

Whelan, E., Teigland, R., Donnellan, B. and Golden, W., (2010) How Internet technologies impact information flows in R\&D: Reconsidering the technological gatekeeper. $R \& D$ Management, 40(4), 400-413.

Wynarczyk, P., Piperopoulos, P. and McAdam, M. (2013) Open innovation in small and medium-sized enterprises: An overview. International Small Business Journal, 31(3), 240255.

Wolff, J. A., and Pett, T. L. (2006). Small-firm performance: modeling the role of product and process improvements. Journal of Small Business Management, 44(2), 268-284.

Xia, T., and Roper, S. (2016). Unpacking open innovation: absorptive capacity, exploratory and exploitative openness, and the growth of entrepreneurial biopharmaceutical firms. Journal of Small Business Management, 54(3), 931-952.

Yoo, Y., Boland Jr, R. J., Lyytinen, K., and Majchrzak, A. (2012) Organizing for innovation in the digitized world, Organization Science, 23(5), 1398-1408.

Zahra, S. A., and George, G. (2002) Absorptive capacity: A review, reconceptualization, and extension, Academy of Management Review, 27(2), 185-203.

Zuiderwijk, A., Janssen, M., Choenni, S., Meijer, R. and Alibaks, R.S., 2012. Socio-technical Impediments of Open Data. Electronic Journal of e-Government, 10(2). 
This is the author's post-print copy of the article published on

R\&D Management

https://doi.org/10.1111/radm.12347

Figure 1: Open data acquisition and assimilation

First-order categories

(illustrative quotes) "last time I checked, there was something like 8,000 or 9,000 datasets
available on data.gov, so it's pretty difficult to stay on top of new data sources
$[$ [... we just don't have the time and resources." (Case 8)
say "Look, we've got 45,000 datasets, isn't that great... But it's very much a
case of push it out, push it out, push it out... But then, that's what also adds
the value to the market, because other companies wouldn't have these skills
and expertise to keep following these things." (Case 7)

"Ultimately end up ... with one or two enthusiasts within the organisations that really want to do it [using $O D$ ], but they still have to convince their own

management that it's a good idea... So yes, there are often various objections about things like "Well, so it's going to cost us money; what's in it for us?" is one obvious thing. Or problems about - they are worried of the data quality or they're worried about people misunderstanding it or misusing it, these kind of things" (Case 19)

"Wealso interact with businesses using open data, particularly through the ODI, which is obviously quite an essential point for those businesses. So that enables us, I guess, to find out who is publishing interesting data and to share ideas about how to use it. when we are setting something up with an open data source, we will informally probably discuss with the publisher, and also with the client" (Case 14)



"[We] used to pay for these mountains of data we are getting now for free they will simply add more value in different areas of the business." (Case 9) "II's free! But I mean, then it's - yeah. It's free. So it means that as an organisation or a business, you can get access to information that hitherto would have cost a hell of a lot of money" (Case 5)

\section{"so we couldn't do it without open data"}

(Case 30)

"But generally speaking. I think if there hadn't been at least a lot of open data datasets available, we probably wouldn't have had the product in the first

place" (Case 23) 
This is the author's post-print copy of the article published on

R\&D Management

https://doi.org/10.1111/radm.12347

Figure 2: Open data transformation

First-order categories

(illustrative quotes)

Second-order themes

Aggregate dimensions

"Our main problem is that whilst open data is our friend, it is also can be a

double edged sword, because at the moment we're working across 45

countries, so that you can imagine the amount of different municipalities, cities

organisations in those countries, and we're having to put all the data into one

standard format that we can then use internally. So that in itself presents a big

problem..." (Case 16)

"П] create something of interest, it takes work, effort and time. Are they going

to have three or four developers sat there monitoring new data releases,

collecting the data, explaining it to other people? Probably not, and if they do,

it would only be the very top group of companies that do that, so there's still

quite a vast market undemeath that..." (Case 25)

"[They've] thrown all this data out there, I feel that we haven't got the resources to work with that data to understand it." (Case 15)

"There aren't any data scientists. There aren't. It's so hard to find Yeah, but

there just aren't any. It's only recently that data has become sexy. [...] No, it's

a vastly under resourced area, in my experience. They're very hard to get" (Case 21)

"We are trying to balance the consumer side to being able to think like the consumer, which is kind of let's say more qualitative. On the other hand, we need to understand all the data which is an important quantitative type skill. So in the team we need both the splits" (Case 16)

"One of the hardest jobs we had to recruit was a data analyst with marketing focus" (Case 2)

"So you need that mix of data scientist [and] practitioner. So then you can then say "This is what I want."... We've reached the point where look,....just stop proving the technology, let's start doing something with this information It has to be demand driven" (Case 30 )

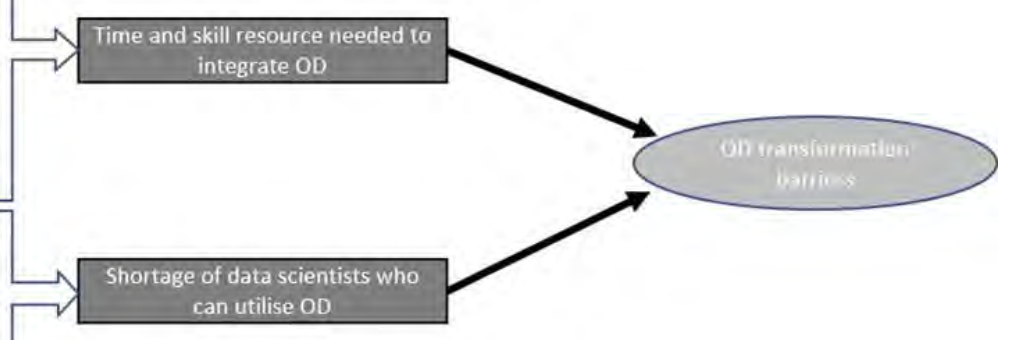

"It's sort of secondary and tertiary uses where individuals and private

companies like ours can take this [OD] and smash it up and create some new weird and wonderful tool for the private market. [We use] open data as a

foundation, but the value that people get from that data is...combining that with other types of [proprietary] data. (Case 8)

"Look, this is what other people are doing, and on their own [OD] has mediocre

value, but when meshed together [with other data], it has an exponential

value." (Case 2)

\section{Ability to hire, retain and integrate} a mix of talent

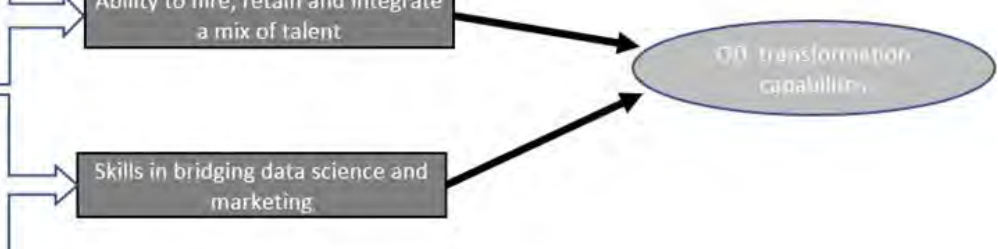


This is the author's post-print copy of the article published on

R\&D Management

https://doi.org/10.1111/radm.12347

Figure 3: Open data exploitation 
This is the author's post-print copy of the article published on

$\mathrm{R} \& \mathrm{D}$ Management

https://doi.org/10.1111/radm.12347

"I think there's really one major risk, which is continuity of supply. So if we based the business on using open data, which we are obviously not paying for, then it's very difficult for us to have any lever to ensure that that data
continues to be available. So political changes, or if an organisation changes its mind about publishing. we are likely to be a bit stuck..." It would probably kill any product using that data." (Case 12)

"Well at that time I was doing some work with $[x]$ and we'd put a lot of effort into preparing for the next flow survey [Open Data]. We had developed a prototype [app], everyone loved it, and then it [Open Data] got pulled" (Case 5)

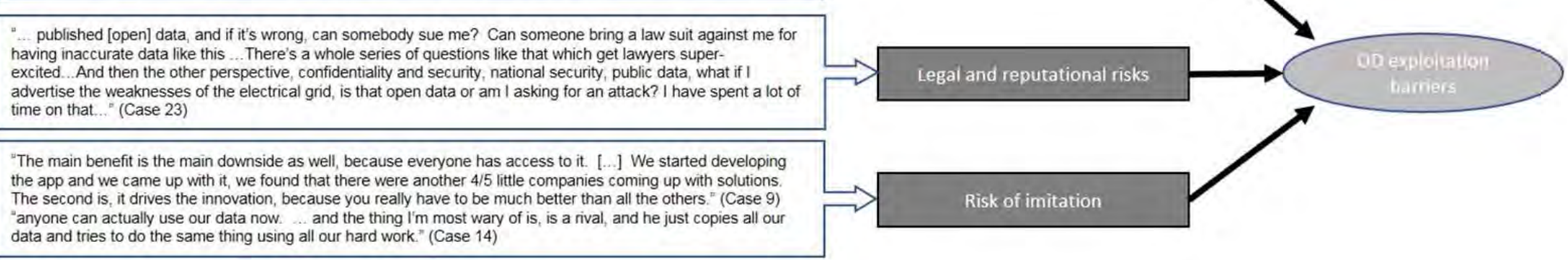

,it dives the innovation, because you really have to be much better than all the others." (Case 9 ) "anyone can actually use our data now. and the thing 'm most wary
data and tries to do the same thing using all our hard work." (Case 14) "I... Iit's mentally how you think about your business. It's to commit to doing things openly, is technically and
physically very easy. [.... To committ to being open as a business is a much harder thing, because it requires you
to do loads and loads of workl" (Case 19)

\section{$\Rightarrow$}

Uncertainty in future availability

of $O D$

"I mean it's open source, so they can do that [stealing ideas] if they wish to. I guess there are 2 protections that we
have in reality. Number 1 protection is we have relationships with our clients, so once we have that relationship it's
difficult for someone else to copy our product and hence try and steal that relationship" (Case 12)

"we continue to innovate, so somebody can copy what we are doing now, but then they have to continue to copy any new innovations." (Case 12)

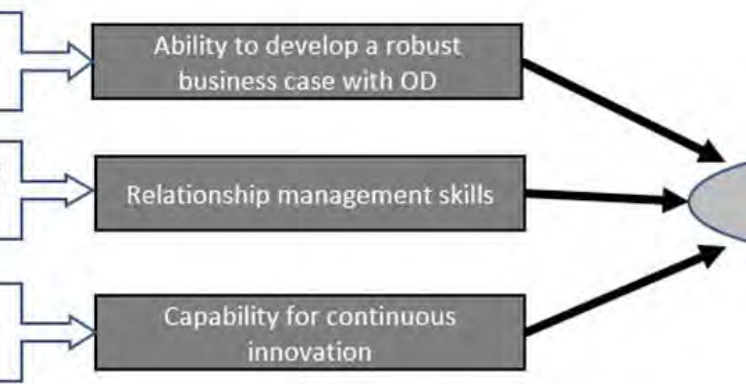

We have our published [OD] channels... start-ups in foreign countries [.. . particularly in areas like India... it was an area for us to go into their market without heavy investment, because all we

someone else does all the work, and turns it into a development. (Case 2)

Also because it benefits our business so that the way we make money is we make our database avaliable and
people click on properties, and we then send those leads on to our customers. So the more people I can get seeing my database the better... if someone can generate a significant amount of traffic for us, we'll gladly pay them for that" (Case 8)

"No, basically to start this kind of business and to gain this exposure that we gained, I would have either had to do it somewhere else in a different country that had open data, or perhaps invest something close to $£ 200,000$,

$£ 300,000$, which was definitely out of the question! Yeah, it wouldn't be possible" (Case 24)

...it wouldn't be viable. Absolutely not. It does remove a large chunk of the operating costs, there's no doubt about that. But, some datasets have been made available that just weren't available... But that's not to say that just Coutve got to be user led,

consumer ed, to think what people want rather than "l've made this amazing thing build it and they will come."




This is the author's post-print copy of the article published on $\mathrm{R} \& \mathrm{D}$ Management

https://doi.org/10.1111/radm.12347

Figure 4: Open data absorptive capacity framework overview




This is the author's post-print copy of the article published on

R\&D Management

https://doi.org/10.1111/radm.12347

Appendix 1: Research Participants

\begin{tabular}{|c|c|c|c|c|c|c|}
\hline Case & $\begin{array}{c}\text { Organisation } \\
\text { Type }\end{array}$ & Sector $^{2}$ & Interviewee & $\begin{array}{l}\text { Publish } \\
\text { OD } \\
\text { (outbound } \\
\text { Ol) }\end{array}$ & $\begin{array}{c}\text { Consume } \\
\text { OD } \\
\text { (inbound } \\
\text { OI) }\end{array}$ & $\begin{array}{c}\text { Face to } \\
\text { FacelSkypel } \\
\text { Telephone } \\
\text { interview }\end{array}$ \\
\hline 1 & Corporation & Engineering & $\begin{array}{c}\text { Product/innovation } \\
\text { manager }\end{array}$ & No & Yes & Face to face \\
\hline 2 & SME & Retail & $\begin{array}{c}\text { Product/innovation } \\
\text { manager }\end{array}$ & Yes & Yes & Face to face \\
\hline 3 & $\begin{array}{l}\text { Public } \\
\text { agency }\end{array}$ & N/A & Head of Data & Yes & No & Face to face \\
\hline 4 & SME & $\begin{array}{l}\text { Business } \\
\text { services }\end{array}$ & Owner-manager & No & Yes & Telephone \\
\hline 5 & Foundation & $\begin{array}{l}\text { Business } \\
\text { services }\end{array}$ & Head of Data & No & Yes & Skype \\
\hline 6 & $\begin{array}{l}\text { Public } \\
\text { agency }\end{array}$ & N/A & Head of Data & Yes & No & Telephone \\
\hline 7 & SME & $\begin{array}{l}\text { Business } \\
\text { services }\end{array}$ & Director & Yes & Yes & Skype \\
\hline 8 & SME & $\begin{array}{l}\text { Business } \\
\text { services }\end{array}$ & Director & Yes & Yes & Face to face \\
\hline
\end{tabular}

\footnotetext{
${ }^{2}$ Sector information is not provided for government departments as this would identify the organisations and potentially the interviewees, violating participant anonymity.
} 
This is the author's post-print copy of the article published on

R\&D Management

https://doi.org/10.1111/radm.12347

\begin{tabular}{|c|c|c|c|c|c|c|}
\hline 9 & SME & $\begin{array}{l}\text { Business } \\
\text { services }\end{array}$ & Director & Yes & Yes & Skype \\
\hline 10 & $\begin{array}{l}\text { Public } \\
\text { agency }\end{array}$ & $\mathrm{N} / \mathrm{A}$ & $\begin{array}{c}\text { Product/innovation } \\
\text { manager }\end{array}$ & Yes & No & Face to face \\
\hline 11 & SME & Consultancy & Owner-manager & No & Yes & Skype \\
\hline 12 & SME & Consultancy & Owner-manager & Yes & Yes & Face to face \\
\hline 13 & $\begin{array}{l}\text { Public } \\
\text { agency }\end{array}$ & $\mathrm{N} / \mathrm{A}$ & Head of Data & Yes & No & Skype \\
\hline 14 & SME & $\begin{array}{c}\text { Software } \\
\text { development } \\
\text { and services }\end{array}$ & Owner-manager & No & Yes & Skype \\
\hline 15 & SME & Retail & $\begin{array}{c}\text { Product/innovation } \\
\text { manager }\end{array}$ & No & Yes & Telephone \\
\hline 16 & SME & Real estate & Owner-manager & Yes & Yes & Face to face \\
\hline 17 & SME & Leisure & Owner-manager & Yes & Yes & Face to face \\
\hline 18 & $\begin{array}{l}\text { Public } \\
\text { agency }\end{array}$ & $\mathrm{N} / \mathrm{A}$ & $\begin{array}{c}\text { Product/innovation } \\
\text { manager }\end{array}$ & Yes & Yes & Face to face \\
\hline 19 & SME & $\begin{array}{c}\text { Software } \\
\text { development }\end{array}$ & Director & Yes & Yes & Skype \\
\hline 20 & SME & $\begin{array}{l}\text { Business } \\
\text { services }\end{array}$ & $\begin{array}{c}\text { Product/innovation } \\
\text { manager }\end{array}$ & Yes & Yes & Telephone \\
\hline 21 & SME & Software & Software & No & Yes & Face to Face \\
\hline
\end{tabular}


This is the author's post-print copy of the article published on

R\&D Management

https://doi.org/10.1111/radm.12347

\begin{tabular}{|c|c|c|c|c|c|c|}
\hline & & development & developer & & & \\
\hline 22 & SME & $\begin{array}{l}\text { Business } \\
\text { Services }\end{array}$ & Director & Yes & Yes & Skype \\
\hline 23 & SME & Consultancy & Owner-manager & Yes & Yes & Skype \\
\hline 24 & SME & $\begin{array}{c}\text { Software } \\
\text { development }\end{array}$ & Owner-manager & Yes & Yes & Skype \\
\hline 25 & SME & $\begin{array}{l}\text { Business } \\
\text { Services }\end{array}$ & Director & Yes & Yes & Telephone \\
\hline 26 & Corporation & Retail & $\begin{array}{c}\text { Product/innovation } \\
\text { manager }\end{array}$ & No & Yes & Face to face \\
\hline 27 & SME & Consumer & $\begin{array}{c}\text { Product/innovation } \\
\text { manager }\end{array}$ & No & Yes & Face to face \\
\hline 28 & Corporation & Consultancy & Director & No & Yes & Face to face \\
\hline 29 & SME & Consultancy & Director & Yes & Yes & Skype \\
\hline 30 & SME & Consultancy & Owner-manager & Yes & Yes & Face to face \\
\hline
\end{tabular}

